\title{
The Influence of Reproductive History on Post-Reproductive Mortality: A Case Study of Amish Women
}

\author{
Rachel E. Stein \\ Associate Professor, Sociology and Anthropology \\ West Virginia University \\ rachel.stein@mail.wvu.edu \\ Katie E. Corcoran \\ Associate Professor, Sociology and Anthropology \\ West Virginia University \\ kecorcoran@mail.wvu.edu \\ Carina Perrone \\ Graduate Teaching Assistant, Sociology and Anthropology \\ West Virginia University \\ cp0102@mix.wvu.edu \\ Jeralynn S. Cossman \\ Dean, College for Health, Community, and Policy \\ University of Texas at San Antonio \\ Lynne.Cossman@utsa.edu
}

\begin{abstract}
The reproductive choices women make affect their health outcomes; however, the relevance of reproductive history on post-reproductive mortality varies according to the population under study. We examine whether the number of children a woman gives birth to, short birth intervals, late childbearing, having twins, and having children who die young have an influence on maternal mortality among the Amish. We use information from Amish directories to examine reproductive patterns of 228 women in this high fertility group. Our results indicate the patterns typically found for maternal mortality in the general population do not hold in our sample of Amish women. We suggest the mediating role of family and community is integral to understanding the maternal health patterns within the Amish community.
\end{abstract}

Submitted November 9, 2020; accepted April 27, 2021; published October 8, 2021

https://doi.org/10.18061/jpac.v2i1.7993

Keywords: Amish, maternal health, mortality

$\mathrm{T}$ he Amish are noted for their high fertility rates (Colyer et al., 2017; Cross \& McKusick, 1970; Donnermeyer, 2015; Donnermeyer et al., 2013; Ericksen et al., 1979; Greksa, 2004; Greksa, 2002; Hewner, 1998; Stevenson et al., 1989). As a natural fertility population, the timing and decision of births among the Amish population is not influenced by decisions to limit family size (Greksa, 2004, 2002). In fact, the religious beliefs of most Amish groups do not allow for the use of contraceptives (Cross \& McKusick, 1970; Greksa, 2002). Stevenson et al. (1989) note the 
Amish population has stable rates of growth over time. Donnermeyer (2015) indicates the Amish population is expanding and is expected to double approximately every 20 years.

While studies consistently reference the growing Amish population, there is limited attention focused on the influence of large family size on women's health. Some studies have looked at health more generally. Miller et al. (2007), for example, indicate the physical health of Amish women is similar to that of non-Amish women. In contrast, Fuchs et al. (1990) indicate Amish women have higher rates of obesity than non-Amish women. Fuchs et al. note the obesity trends might be related to the number of children born, but do not explore this route of inquiry. Neither of these studies explores how reproductive history affects maternal health.

In addition to general physical health, research has explored mental health among the Amish. From this research, we gain an understanding of the importance of community within the Amish population. Amish women tend to report lower levels of stress and depression than their nonAmish counterparts. Miller et al. (2007) attribute the positive mental health outcomes to the high levels of support available to Amish women within their community. The emphasis on creating communities in which Amish people are active and connected members serves as a health benefit (Mitchell et al., 2012). The emphasis on small community structure benefits Amish health in terms of longevity and reproductive success (Hewner, 1998).

Greksa (2002) explores patterns of childbirth over time in the Geauga County Amish settlement and finds women in more recent birth cohorts tend to get married and have children at slightly earlier ages as compared to older cohorts, while age at the birth of the last child has remained consistent over time. Greksa's study establishes the Amish in Geauga County as a natural fertility population, but does not indicate maternal health outcomes that result from changes in childbirth patterns. In a historical comparison of Mennonite congregations from 1825 to 1924, St. George et al. (2000) indicate short birth intervals and late childbearing negatively affect health; however, the focus is on childhood mortality, not the health risks associated with mothers.

In the current study, we explore how reproductive choices affect post-reproductive mortality in a sample of Amish women. Many women in Amish communities get married and have children (Hostetler, 1993; Hurst \& McConnell, 2010). In addition, many women do not migrate or divorce. As such, they provide an excellent sample from which to examine how reproductive choices might influence maternal health, specifically mortality. Understanding the linkages between reproductive choices and health can help health practitioners provide appropriate care to women. This is especially important among the Amish population, as the Amish generally do not seek preventive medical care, including prenatal care (Fox-Kuhner, 2008; Lucas et al., 1991). Also important to consider is the active role of the family and community, as these are often driving factors in health behaviors (Dorsten, 1994).

\section{Maternal Health}

Women's health outcomes are often measured by mortality, with certain reproductive choices, including having many children and short birth intervals, leading to shorter lifespans (Barclay \& Kolk, 2017, 2019). The number of children a woman gives birth to is tied to biological and social 
implications. Much of the research on the relationship between number of children and postreproductive mortality indicates a J- or U-shaped relationship (Barclay \& Kolk, 2019; Doblhammer, 2000; Högnäs et al., 2017; Hurt et al., 2006; Read et al., 2011; Zeng et al., 2016). That is, women with many children have shorter life spans as compared to women with two to three children. Similarly, women with two to three children live longer than women with only one child or no children. Women who give birth to one child may have complicating health problems related to the first pregnancy. These complications might prevent or discourage them from having more children (Grundy \& Tomassini, 2005). Biologically, women who have many children are at lower risk of certain types of cancers, due to changes in hormone production during pregnancy and lactation (Barclay et al., 2016; Barclay \& Kolk, 2019; Merrill et al., 2005). Even so, certain theoretical frameworks, including the maternal depletion hypothesis, suggest having more children is a direct physiological drain on mothers and decreases life expectancy (Barclay \& Kolk, 2019).

Additionally, there are social implications tied to the number of children in a family. Parenting can have many benefits including enhanced social networks and a potential source of social support, especially in the long term (Grundy \& Shelton, 2001; Grundy \& Tomassini, 2005). Parenthood also includes the stressors associated with raising children, economic costs, and reduced opportunities for fulfilling other roles (Friedman \& Mare, 2014; Grundy \& Tomassini, 2005; Joshi, 2002; Torssander, 2013; Zimmer et al., 2016). Studies that focus on the negative consequences of having many children often quantify "many children" as five or more (Barclay \& Kolk, 2019; Grundy \& Tomassini, 2005). While there are varied levels of support for the relationship between many children and increased risk of mortality, research is generally limited by the inclusion of few families with five or more children (Barclay \& Kolk, 2019).

In addition to the number of children born, raising multiple closely spaced children can affect the physical, emotional, social, and financial resources of parents. The World Health Organization recommends women wait at least 24 months before trying to conceive after the birth of a child, as research indicates negative health consequences for women who conceive before this time frame (Barclay \& Kolk, 2017). In addition to physiological consequences of short birth intervals, the strains associated with raising multiple children close in age are compounded for parents with little social support (Grundy \& Kravdal, 2014). Closely spaced births can lead to increased risk of partnership disruption, which can have a negative effect on health (Grundy \& Tomassini, 2005). Related, the stressors associated with raising twins with limited social support increases health risks. Mothers with short birth intervals and multiple births have elevated risk of mortality (Grundy \& Kravdal, 2014; Grundy \& Tomassini, 2005). Missing from much of the research on maternal mortality is the consideration of stillborn children or children who die within their first year of life. Winikoff (1983) indicates problems with measuring birth intervals, which often do not account for the presence of stillbirths or abortions. These elements might be considered indicators of maternal health, but are often not included, largely due to lack of available data.

Research on how late childbearing affects health has been inconsistent. In a study of the U.S. population, Cooper et al. (2000) indicate women who give birth after the age of 40 have higher mortality risk; however, other studies find late pregnancy positively affects maternal health 
(Grundy \& Tomassini, 2005; Westendorp \& Kirkwood, 1998; Yi \& Vaupelly, 2004). Research on women in China, for example, indicates having several children after the age of 35 or 40 is beneficial for the longevity for women (Yi \& Vaupelly, 2004). The inconsistency in the research findings can be due, in part, to the differences in methodology used to control for socioeconomic status and marital status.

\section{Current Research}

While some overarching trends emerge, studies on maternal mortality have been inconsistent, in part due to the complexity of the links between reproductive history and post-reproductive mortality (Barclay et al., 2016). In addition, research has used a range of methods and populations with varying controls for socioeconomic and sociodemographic characteristics (Grundy \& Tomassini, 2005). Studying maternal mortality within the Amish allows greater consistency across the sample. Amish have generally consistent patterns of age at marriage, division of labor by gender, and child-rearing practices. Divorce is mostly unheard of among the Amish. They are also homogeneous in their level of education, as the Amish are limited to an eighth-grade education (Dorsten, 1994; Hostetler, 1993).

In the current study, we explore how the number of children a woman gives birth to affects post-reproductive mortality. Using a sample of Amish women allows us to explore the relationship more fully between having large families and maternal mortality. The Amish are a natural fertility population, which indicates they generally do not use methods of birth control (Cross \& McKusick, 1970; Greksa, 2002). As such, the Amish have relatively large families. While the average number of children for non-Amish families in the United States is approximately two children (U.S. Census Bureau, n.d.), Kraybill et al. (2013) indicate the average number of children for Amish families is seven (Ericksen et al., 1979). In a study of Holmes County Amish, Colyer et al. (2017) report the median number of children remained constant at six from 1965 to 1996 and then declined to five children in 2000 and 2005 with a further decline to four children in 2010. Of note, abortions are not permitted within the Amish belief system (Kraybill et al., 2013). Even with declining births, the Amish generally have larger families than the non-Amish in the United States. While most research on post-reproductive mortality is limited by small family size, examining a sample of Amish women allows us to consider reproductive choices within relatively large families. We also

assess how short birth intervals, late childbearing, having twins, and having stillborn children affect post-reproductive mortality. We control for the birth cohorts of women in the study, as women who grew up during different decades may experience different economic and social expectations.

\section{Data}

A record of the families who reside in church districts in the Holmes County, Ohio, Amish settlement was started in 1955 with the documentation of the heads of household in Amish directories. The heads of household are primarily men, except in the rare cases of unmarried women. Spouses and children are recorded in directories starting in 1965. Widows are listed under 
their (late) husband's name until their death. The directories include demographic information for the male head of household and his spouse and children, including birth and death dates, along with the marriage date for the head of household.

We use the 1973 Ohio Amish Directory, Holmes County and Vicinity to create a sample of Amish women. The 1973 directory includes 72 church districts. We randomly chose eight districts to use in our sample, which represents approximately $11 \%$ of the 1973 directory population. Each of the eight districts have an average size of 34 families per district. The largest district in our sample had 49 families and the smallest district had 22 families in 1973. Women are the unit of analysis in this study and include spouses of the heads of household and women who have never married. Women who have never married are listed as head of household in the directories. There are 276 women listed across the eight districts in 1973 . We track these 276 women over time, using directories from 1981, 1988, 1996, 2000, 2005, 2010, 2015, and 2020 to identify information about their children and death dates. Families continue to be listed in the directory provided one of the spouses is alive. If the husband dies, for example, the wife and children remain listed in the directory under the husband's name. The husband's death date is published in the directory. The same is true if the wife dies first - the husband and children remain in the directory and the wife's death date is published. When the surviving spouse dies, the family's entry is no longer included in the directory. To complete the data with death dates for the women who survived their husbands, we used Ancestry.com and FamilySearch.com to find death records. We were unable to find death dates for 11 women. Nineteen women were not listed in directories beyond 1973, suggesting the family may have moved out of the Holmes County settlement or left the Amish faith. We exclude single women with no children (11 total) and married women with no children ( 3 total), as our focus is on how childbearing affects maternal health. We focus on women who died after the age of 45 to capture post-reproductive mortality; this excludes four women who died before their 45 th birthday. Our final sample includes 228 women with complete information.

\section{Methods}

To examine whether mortality follows a J- or U-shaped distribution among our sample, we present a scatterplot graph that captures the age of death of women based on the number of children born. A J- or U-shaped distribution would indicate women with zero or one child have a higher mortality than women with two to four children. Additionally, women with five or more children would also have a greater risk of mortality than those with two to four children. We then present a series of figures that represent the results of the bivariate statistics. The figures depict patterns and comparisons across groups of women in the sample. The bivariate statistics include the average age of death by each of the independent variables - the number of children born, short birth intervals, late childbearing, having twins, and having a child who died young. We also present a figure for the average age of death by birth cohorts to indicate the pattern that emerged. We calculated difference of means statistical tests (ANOVA, $t$ tests) to assess statistical differences across groups; the results of the tests of significance are available upon request. 
We are interested in testing a set of covariates on the time till death. As such, Cox proportional hazards models are ideal as they allow for estimating the time till death as a function of covariates without specifying the underlying baseline hazard rate (Allison, 1984; Box-Steffensmeier \& Jones, 2004). We measure duration in years and months from when a woman turns 45 years old until she dies. Most of the women in the sample do not bear children after age 45. The average lifespan is 78 years. There are 228 women in the sample, with 142 that died after the age of 45 . This means that 86 cases are censored; that is, these women did not die by the end of the period under study. We model the mortality rate (i.e., hazard rate) as a function of a set of predictors. The hazard rate refers to the rate of death per time unit between the interval of $t$ and a future value of $t$ contingent on a woman surviving to or beyond time t. We do not theorize variation in the hazard rate across time (i.e., time dependence) and thus are able to use the Cox semiparametric proportional hazards model (Cox, 1972). We tested the proportional hazards assumption for each model, and the results indicate that the assumption is reasonable (Allison, 1984).

\section{Variables}

Existing research indicates several variables that capture reproductive history influence postreproductive mortality, including the number of children, short birth intervals, late childbearing, having twins, and having stillborn children or children that died young. We use the latest directory in which information is available for each family to create these children-centric variables. This ensures all children are included, as the last available entry lists the woman and her spouse at an age beyond childbearing years.

The number of children is a count variable that ranges between 1 and 12 or more. Because the number of women who had more than 12 children is relatively small, we collapsed the last age category of $12+$ children to include women who had 12, 13, 14, 15, or 16 children. Some research on post-reproductive mortality indicates there is a difference between women with more than five children as compared to women with fewer than five children (Barclay \& Kolk, 2015; Grundy \& Tomassini, 2005). We explore these options with our data but do not find a solid statistical reason to create a cutoff point in terms of a maximum number of children. As such, we include the count variable to assess the number of children in our models.

Previous research suggests short birth intervals between the first two children can lead to greater risk of early mortality (Berg \& Rotkirch, 2014; Grundy \& Kravdal, 2014). Based on the suggested birth intervals of 24 months identified by the World Health Organization, Barclay and Kolk (2017) identify birth intervals 18 months or shorter as high risk to the mother (Grundy \& Tomassini, 2005). We use this benchmark for the current study. Short birth intervals are reported in years and months and are calculated by dividing the total reproductive span by the total number of children. While some research indicates a long reproductive span can increase the risk of early mortality (Cooper et al., 2000), others indicate having children after the age of 39 can extend life expectancy (Grundy \& Tomassini, 2005; Westendorp \& Kirkwood, 1998; Yi \& Vaupelly, 2004). We include a measure of late childbirth, indicating whether a woman gave birth after the age of 39 (giving birth to all children before the age of 39 serves as the control category). Having multiple 
births can be harmful to women's health (Grundy \& Kravdal, 2014; Grundy \& Tomassini, 2005). Similarly, having stillborn children or children who died before the age of 1 can have negative health consequences (Winikoff, 1983). We include a measure of multiple births ( $1=$ birthed twins) and having at least one child with an early death $(1=$ stillborn or died before the age of 1$)$.

The birth cohort of women in the sample may influence the age of death, as the women are faced with different access to health care, social concerns, and environmental concerns dependent on when they were born. The sample includes women born across a 70-year time span, from 1883 to 1953 . We collapse the birth years into categories of birth cohorts. These include women born between 1883-1909 (1900s cohort), 1910-1919 (1910s cohort), 1920-1929 (1920s cohort), 19301939 (1930s cohort), and 1940-1953 (1940s cohort).

\section{Results}

Table 1 presents the descriptive results of the dependent and independent variables. The sample is limited to women who died after the age of 45 . Approximately $62 \%$ of the women in the sample died before 2020. The average age of death was 79 , with a range from 51 years to 99 years. Women in the sample had, on average, seven children. About $40 \%$ of the women in the sample had birth intervals shorter than 18 months; $40 \%$ of women in the sample had children after the age of 39 . Only $9 \%$ of the sample of women had twins, while almost $19 \%$ had a child who was stillborn or died before the age of 1 .

Table 1

Descriptive Statistics $(N=228)$

\begin{tabular}{|c|c|c|c|c|c|c|}
\hline & $n$ & Mean & & & Min & Max \\
\hline Age of death & 142 & 79.45 & & & 51.24 & 99.41 \\
\hline \multirow[t]{3}{*}{ Number of children } & 228 & 6.96 & & & 1 & 12 \\
\hline & \multicolumn{2}{|c|}{ Yes } & \multicolumn{2}{|c|}{ No } & & \\
\hline & $n$ & $\%$ & $n$ & $\%$ & Min & Max \\
\hline Women died & 142 & 62.28 & 86 & 37.72 & 0 & 1 \\
\hline Short birth Intervals ( $<=18$ months) & 92 & 40.35 & 136 & 59.65 & 0 & 1 \\
\hline Late childbirth (>=39 years) & 91 & 39.91 & 137 & 60.09 & 0 & 1 \\
\hline Twins & 21 & 9.21 & 207 & 90.97 & 0 & 1 \\
\hline Child with an early death & 43 & 18.86 & 185 & 81.14 & 0 & 1 \\
\hline \multicolumn{7}{|l|}{ Birth cohorts } \\
\hline $1900 \mathrm{~s}$ & 39 & 17.11 & & & 0 & 1 \\
\hline $1910 \mathrm{~s}$ & 37 & 16.23 & & & 0 & 1 \\
\hline $1920 \mathrm{~s}$ & 25 & 10.96 & & & 0 & 1 \\
\hline $1930 \mathrm{~s}$ & 51 & 22.37 & & & 0 & 1 \\
\hline $1940 s$ & 76 & 33.33 & & & 0 & 1 \\
\hline
\end{tabular}


Most studies on how reproductive history affects post-reproductive mortality indicate a J- or U-shaped relationship between the number of children a woman gave birth to and age of death. This relationship would indicate a greater risk of mortality for women with zero or one child and for women with many children. We do not find evidence of this relationship in our sample of Amish women. Figure 1 displays the scatterplot data from the variables age of death and the number of children born. The scatterplot indicates a point on the graph for each of the 142 women in the sample who died. The age of death includes women who died after the age of 45, as these women are likely to have completed their reproductive span. The cutoff age also excludes women who died at younger ages of potential health complications. The scatterplot data indicates a relatively stable pattern in the age of death across women with varying numbers of children.

\section{Figure 1}

Scatterplot of the Age of Death of Women by the Number of Children Born

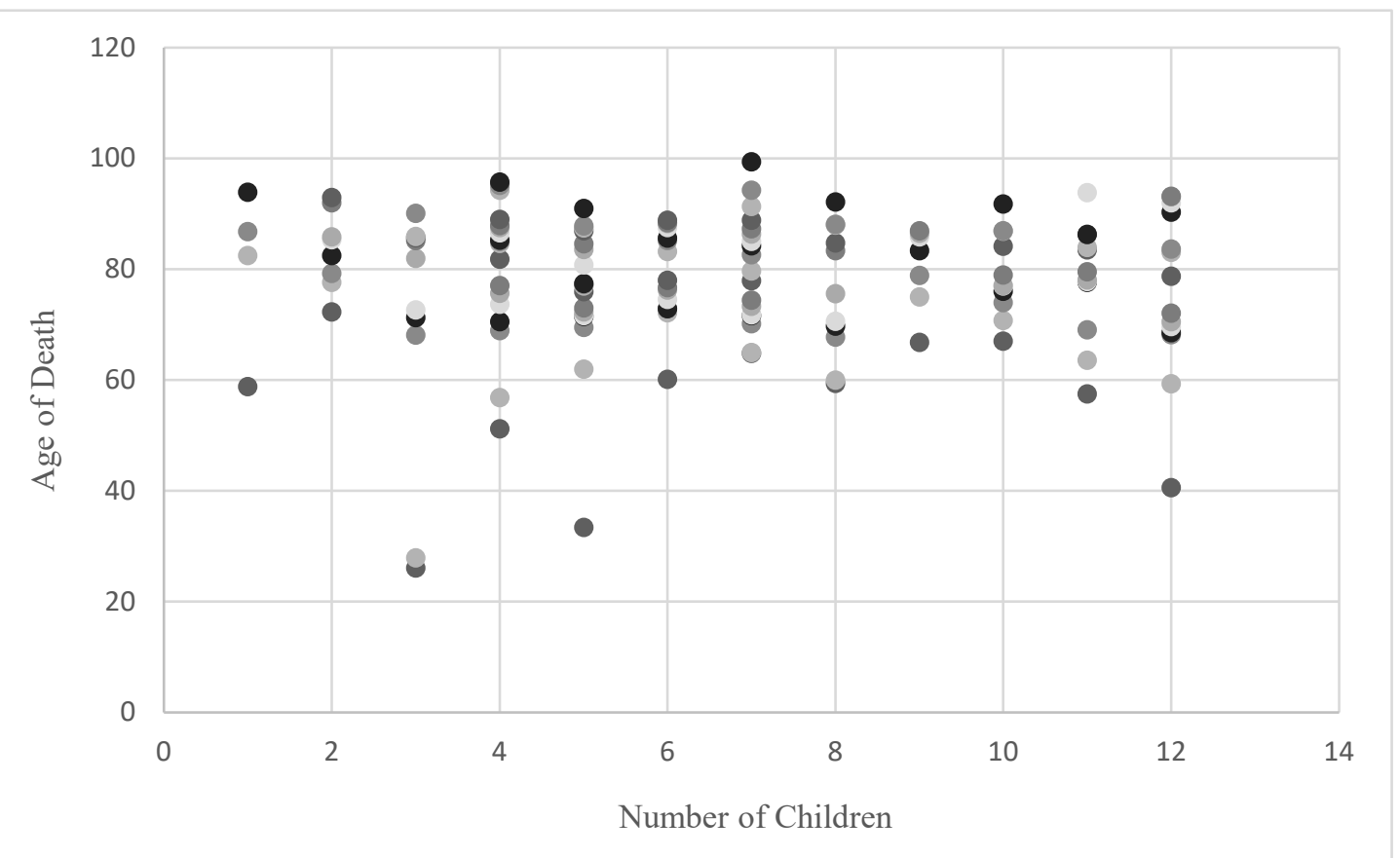

Figure 2 presents the average age of death of women across the number of children born. The overall average age of death for women who died after the age of 45 in the sample is 79 years old. The data in Figure 2 indicate the average age of death across number of children remains relatively consistent with the overall average. There is some variation across number of children; however, the differences are not statistically significant. ${ }^{1}$ Eight women in the sample had two children. The age of death for these women ranges from 72 to 93 . Women with two children lived, on average, slightly longer than the overall mean, 83 years. Eleven women in the sample had eight children,

\footnotetext{
${ }^{1}$ ANOVA results indicate there is not a statistically significant difference across mean age of death across the number of children. ANOVA results are available upon request.
} 
the age of death for these women ranges from 59 to 92 . The average age of death for these women is 76 years, the lowest mean age of death across the number of children.

Figure 2

Average Age of Death of Women by the Number of Children Born

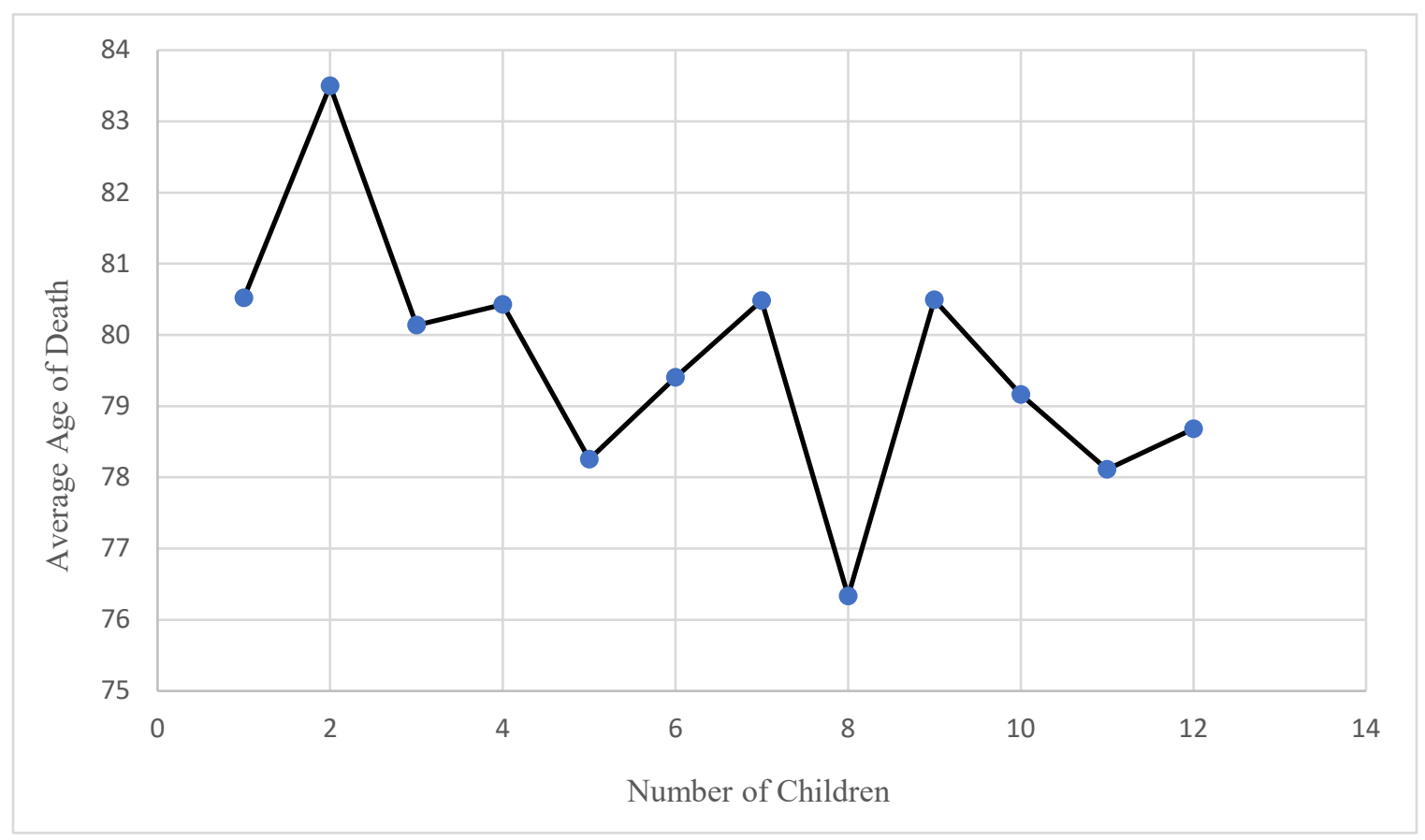

Previous research indicates short birth intervals between the first two children, late childbearing, having twins, and having stillborn children or children who died young influences post-reproductive mortality. Figure 3 displays the average age of death across each independent variable. The average age of death for women with short birth intervals, defined as less than 18 months between their first two children, is 79 years old. This is similar to women with longer birth intervals, who have a mean age of death of 80 . The average age of death for women who gave birth after the age of 39 is 79 years old, which is comparable to the average age of death for women whose reproductive span ended earlier ( 80 years old). The biggest difference in mean age of death is for women who birthed twins. Women who gave birth to twins tend to live, on average, slightly longer than women who did not birth twins (82 and 79 years old, respectively). The mean age of death for women who had a stillborn child or a child who died before their first birthday is similar to women who did not have a child who died young ( 80 and 79 years old, respectively). The mean differences between the groups of women across the reproductive history variables are not statistically significant. $^{2}$

\footnotetext{
${ }^{2} T$-test results indicate there are no statistically significant differences in the mean age of death between women with/without short birth intervals, late childbearing, twins, and children who died young. $T$-test results are available upon request.
} 


\section{Figure 3}

Average Age of Death Across Reproductive History Variables

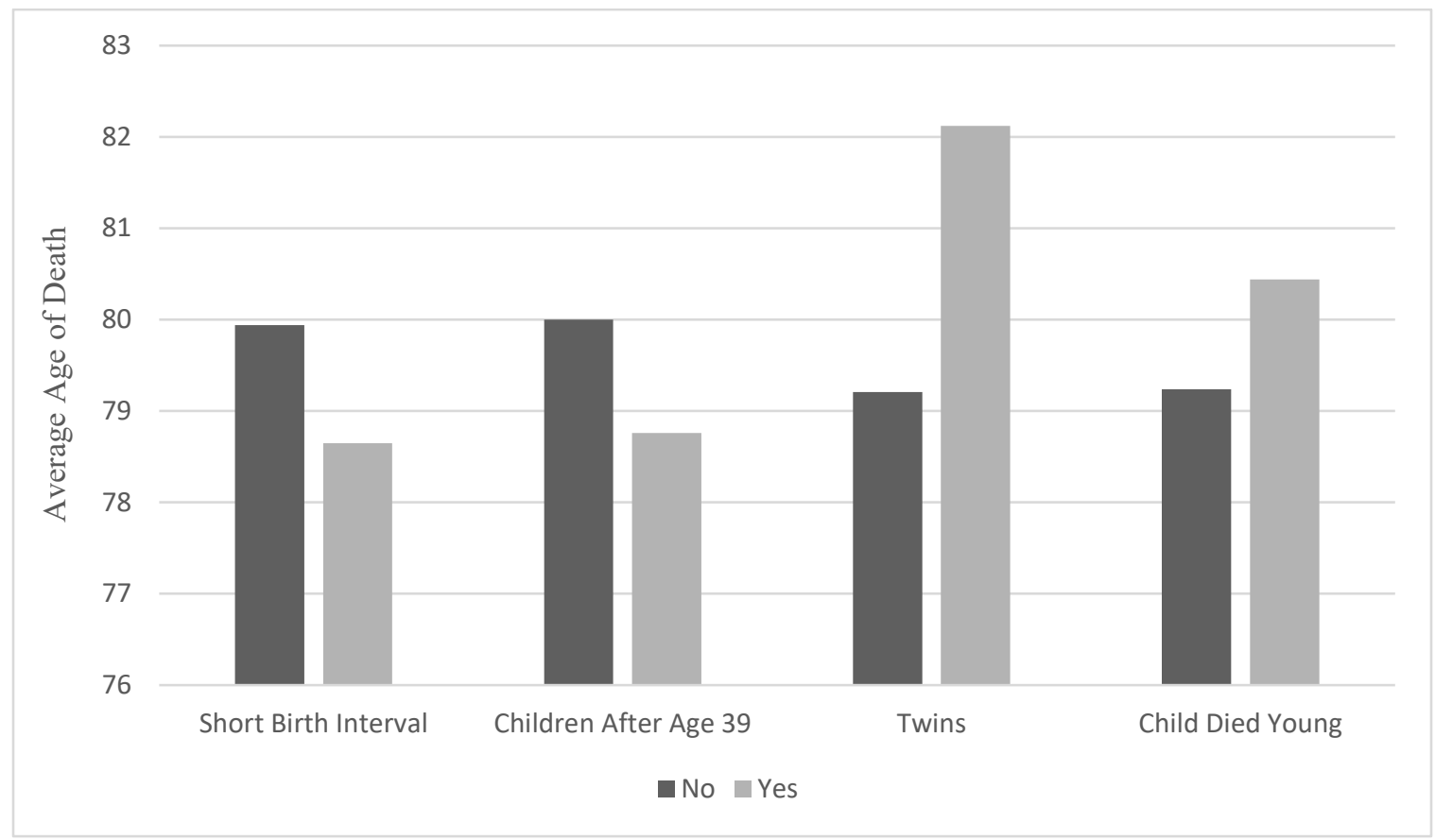

The mean age of death across birth cohorts varies significantly. ${ }^{3}$ Women born in the $1900 \mathrm{~s}$, 1910 s, and 1920s have an average age of death of approximately 83 years old. (See Figure 4.) The average age of death for women born in the 1930s is 75 , while the average age of death for women born in the 1940s is even lower at 69 years. Of note, while the minimum age of death remains relatively consistent across birth cohorts (mostly in the 50s), the maximum age of death for women born in the 1920 s or before reached beyond 90 years old.

\footnotetext{
${ }^{3}$ ANOVA results indicate a statistically significant difference in the mean age of death across birth cohorts. Specifically, women born in the 1940s have a lower average age of death than women born in the $1900 \mathrm{~s}, 1910 \mathrm{~s}$, and 1920s. Women born in the 1930s also have a lower average age of death than women born in the 1900s, 1910s, and 1920s. ANOVA results are available upon request.
} 


\section{Figure 4}

Average Age of Death Across Birth Cohort

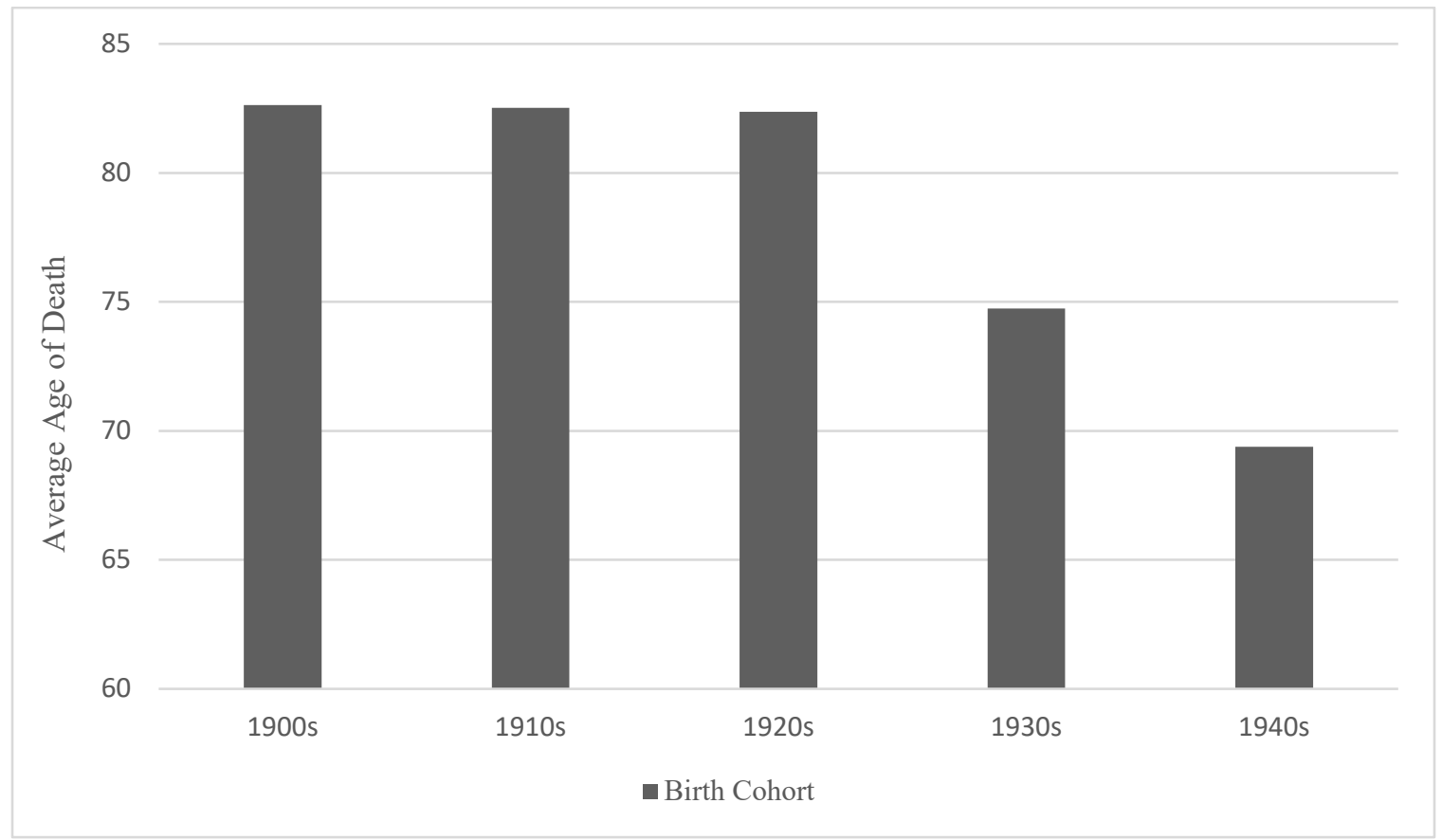

The descriptive statistics and mean comparison tests indicate the independent variables measuring reproductive history do not affect the post-reproductive mortality of the Amish women in our sample. As such, it is not surprising that the same predictive variables do not reach statistical significance in the proportional hazards model. Total number of children, short birth intervals, late childbearing, having twins, and having stillborn children or children that died young do not explain variation in time till death for the women in our sample. Model 1 of Table 2 displays the hazard ratios and $95 \%$ confidence intervals. The results indicate there is not a significant difference between the groups for the predictive variables. Note the confidence interval for each predictive variable includes 1 , which indicates the hazard ratio is not statistically significant. While the bivariate statistics indicate the average age of death varies across birth cohorts, the birth cohort variables do not reach statistical significance in the hazards model. (See Model 2 of Table 2.) Essentially, controlling for other elements of the women's reproductive history accounts for the differences noted in birth cohorts. 
Table 2

Hazard Ratios for Post-Reproductive Mortality in Amish Women $(N=228)$

\begin{tabular}{lcc}
\hline & $\begin{array}{c}\text { Model 1 } \\
\text { HR }(95 \% \mathrm{Cl})\end{array}$ & $\begin{array}{c}\text { Model } 2 \\
\text { HR }(95 \% \mathrm{Cl})\end{array}$ \\
\hline Number of children & $1.02(0.95-1.09)$ & $1.02(0.94-1.09)$ \\
Short birth Intervals (<=18 months) & $0.94(0.66-1.35)$ & $0.95(0.66-1.37)$ \\
Late childbirth (>=39 years) & $0.98(0.64-1.48)$ & $1.02(0.67-1.56)$ \\
Twins & $0.84(0.46-1.55)$ & $0.91(0.49-1.71)$ \\
Child with an early death & $0.92(.059-1.43)$ & $0.89(0.56-1.42)$ \\
Birth cohorts & & \\
$1900 \mathrm{~s}$ & & $0.92(0.47-1.81)$ \\
$1910 \mathrm{~s}$ & & $1.03(0.54-1.96)$ \\
$1920 \mathrm{~s}$ & & $0.68(0.33-1.40)$ \\
$1930 \mathrm{~s}$ & & $1.01(0.53-1.93)$ \\
\hline
\end{tabular}

Note. $\mathrm{Cl}=$ confidence interval.

\section{Discussion}

Overall, our findings do not align with previous literature on how reproductive history affects postreproductive mortality. This misalignment is an important finding. The fact that none of the measures of reproductive history have a statistically significant relationship to the age of death indicates that the role of reproductive variables on mortality operates differently among the sample of Amish women as compared to other populations previously studied. In contrast to many of the studies done on post-reproductive mortality, using a sample of Amish women essentially controls for socioeconomic status, marital status, and level of education. Additionally, the Amish are a natural fertility population; that is, they generally do not use birth control (Cross \& McKusick, 1970; Greksa, 2002). These elements make the Amish an ideal group to assess post-reproductive mortality.

The primary implication from our findings is that there is a great need for additional research on maternal health within the Amish population. The model based on reproductive strains does not provide a good explanation on the risks of maternal mortality for Amish women, which suggests mortality among the Amish is largely influenced by other factors than those traditionally included in studies of maternal health. It could be that we are essentially controlling for levels of inequality within our sample, including socioeconomic status and level of education. These factors may have an influence on how the independent variables affect maternal health for non-Amish women. NonAmish women have greater interaction with the public sphere than Amish women, as Amish women serve as homemakers after marriage. As such, the strains associated with the number of children, short birth intervals, and late childbearing may have a different effect on non-Amish as compared to Amish women. We also might consider how the structure of the Amish settlement, with an emphasis on family and community, mitigates the negative consequences of reproductive strains. 
The current study furthers the research on maternal health in several ways. First, most of the research on the influence of reproductive history on post-reproductive mortality indicates an inverted U- or J-shape applies to the relationship between mortality rates and the number of children. That is, women with zero or one child and women with many children have higher mortality than women with two to four children. We do not find evidence of this relationship in our study. In fact, we find a relatively consistent mean age of death across women, regardless of the number of children born. The consistency in the age of death across the number of children is inconsistent with previous research on post-reproductive mortality and suggests additional factors may be at play in determining Amish maternal health.

Many studies on post-reproductive mortality are restricted by small family size. Several researchers suggest having five or more children is an important marker in terms of women's health. That is, women who have five or more children are at a greater risk for an earlier age of death (Barclay \& Kolk, 2015; Grundy \& Tomassini, 2005). A problem with these studies is that most women included in the research have less than five children. In fact, fewer than $6 \%$ of the women in Grundy and Tomassini's study had more than five children. Studying Amish women allows us to overcome the barrier of small family size, as the Amish are a natural fertility population (Greksa, 2002). As such, Amish families are generally large. As noted in the current research, the median number of children for the women in our sample is 7 , indicating a relatively large family size is the norm for this cohort of women. We do not find statistical evidence that bearing a specific number of children is more harmful to women's health. In contrast, mortality is relatively consistent across women, regardless of the number of children born.

Because large family size is the norm among the Amish, we make note of small family sizes within our sample. While families with one child may be relatively common in studies of Western European countries (Barclay \& Kolk, 2015, 2019; Grundy \& Kravdal, 2014; Grundy \& Tomassini, 2005), only four women in the current study have one child. We note that Amish women with only one child may have experienced other health concerns. The mean age of death for women with only one child, however, is not significantly different than the mean age of death for women with more than one child. This suggests the health concerns these women faced do not directly affect mortality, or do not affect mortality in a way that is different than other types of health concerns women with more children experience.

In contrast to previous research, the current study indicates women with short birth intervals, women who have multiple births (twins), and women with children who were stillborn or died within the first year of life do not differ significantly from women who did not have these reproductive experiences. Each of these factors indicates a potential negative consequence on maternal health. For example, women with short birth intervals do not have appropriate time to recover from the first birth before giving birth to the second child. Similarly, birthing twins has biological implications, as the pregnancy for multiple births is taxing on a woman's body. Closely spaced births also have social implications, as raising children close in age can increase stress levels (Barclay et al., 2016). Stillborn children or children who died before the age of 1 have been used as an indicator of poor maternal health. That is, if the mother is suffering from ill health, she 
could be more likely to have a child who will die young. However, none of these factors are related to risk of mortality among the Amish women in the current study. Previous studies indicate having children late in life can have negative biological implications (Cooper et al., 2000) or, alternatively, can lower post-reproductive mortality risk (Westendorp \& Kirkwood, 1998; Yi \& Vaupelly, 2004). We do not find evidence for either of these arguments in the current study.

While we certainly cannot ignore the biological implications associated with reproductive history, the findings suggest past research has not effectively controlled for variables affecting post-reproductive mortality or did not have enough variation in childbearing to fully analyze the associations. The addition of children to the family is considered a blessing among the Amish and can improve the standing of the family (Hostetler, 1993; Kraybill et al., 2013), but the immediate actions after the birth of a child are not systematically considered. Further research might explore the influence of the community and social support on the relative well-being of women in the Amish community. It is common practice among Amish families to have additional help in the household after having a child (Kraybill, 2001). In many cases, a teen or young unmarried adult niece or cousin will stay with the family to help the new mother with household chores, including the care of the newborn and other children. The expectation that the mother is not solely responsible for the household immediately following the birth of a new child provides an avenue of stress relief that could have positive consequences on maternal health (Kraybill, 2001). Moreover, adult children tend to live near their parents, providing additional social support nearby. Religiosity is often associated with positive health outcomes (Ellison \& Levin, 1998; Kawachi, 2019), but is often ignored in research on post-reproductive mortality. Even while biological factors increase the risk of mortality, social and religious factors mitigate the negative consequences by improving overall well-being. The further exploration of maternal health is an area ripe for research.

Of interest is the declining average age of death over time for the Amish women in our sample. This finding is unexpected, as the general trend for life expectancy in Holmes County and the larger United States has been increasing over time (Arias \& Xu, 2019; Institute for Health Metrics and Evaluation, 2016). We note this difference might be attributed to the changes associated with occupation. While Amish families have traditionally been farmers (Kreps et al., 1994), there has been an occupational shift over the past several decades that have moved male heads of household outside of the home for work. Traditionally, the male head of household helped with raising children, and children were expected to help with farm chores at very young ages (Kraybill, 2001; Nolt, 2016). As occupation shifts away from farming to outside occupations, the primary responsibility for childcare falls to women (Hurst \& McConnell, 2010; Nolt, 2016). As Amish husbands transition to nonfarming occupations, the separation between public and private spheres becomes more distinct. This serves to carve out traditional gender roles, positioning the male into the breadwinner role and the female into the domestic worker role (Hurst \& McConnell, 2010). The husband/father working outside the home provides less social support for the wife/mother, which might negatively affect her health. We do note, however, the overall effect of birth cohort on maternal health is not statistically significant when controlling for other risk factors in our 
models. Corcoran et al. (2020) indicate the shift in occupations also influences congregational exit. The larger implication of occupational shift on mobility within the Amish community and how this might be linked to health outcomes should be explored.

The current study provides information in contrast to the existing literature on the relationship between reproductive history and post-reproductive mortality. Of note, using a sample of Amish women essentially controls for variables affecting the risk factors in the non-Amish population, including socioeconomic status, marital status, and education level. Additionally, the Amish are a natural fertility population, which allows us to explore the relationship between reproductive risk factors and mortality within large families. While we do not find statistical evidence of a negative relationship between reproductive history and mortality for the Amish women in our sample, we do find interesting trends across birth cohorts of women.

There are several limitations to the current study. First, we do not know the cause of death for the women in the sample. That is, we are not aware if the women experienced health complications (long-term illnesses) that may have led to their death. Our findings indicate the need for more research to explore risk factors for maternal health among the Amish. Future research should consider how the family and the community aspects of social support mitigate maternal health risk factors. Second, our sample only includes women from Old Order and Andy Weaver Amish districts in the Holmes County, Ohio, settlement. The Holmes County settlement is comprised of several affiliations including Old Order, New Order, Andy Weaver, and Swartzentruber groups. Among these affiliations, the Swartzentruber groups are classified as the most conservative and the New Order groups as the least conservative. Old Order Amish represent the middle of the conservativism spectrum. The levels of conservatism also vary within these broad groups. The New Order group, for example, can be subclassified as New Order, New Order Tobe, and New Order Christian Fellowship (Hurst \& McConnell, 2010). As such, the conclusions we draw in the current study may not apply across all affiliations. The Swartzentruber Amish, for example, tend to rely more on traditional medicine as compared to the Old Order Amish. Additionally, many Swartzentruber Amish men maintain the traditional occupation of farming as opposed to working outside of the home, which keeps them at home with their families most of the time (Hurst \& McConnell, 2010). These factors likely influence the effect of childbearing on the mortality of Swartzentruber Amish women. The relationship between affiliation and maternal health should be explored in future research.

Finally, our sample of Amish women was drawn from the Holmes County area settlement. This settlement, while located in a rural area, encompasses towns and cities where residents have access to doctors and health care. If any of the women in our sample needed medical care, they would have the option to access care. However, not all Amish settlements in the United States have the same accessibility to medical care (Anderson \& Potts, 2020). The disparities would likely be the most pronounced in settlements comprised of a single district, especially when the district is a conservative group such as the Swartzentruber Amish or Andy Weaver Amish. The differential access to health care services can affect mortality more broadly, but also has implications for health risks linked to childbearing practices. Future research on maternal health risks should consider the 
location of settlements, settlement size, and the affiliation(s) of church districts within the settlement.

\section{References}

Allison, P. D. (1984). Event history analysis: Regression for longitudinal event data. SAGE. https://doi.org/10.4135/9781412984195

Anderson, C., \& Potts, L. (2020). The Amish health culture and culturally sensitive health services: An exhaustive narrative review. Social Science \& Medicine, 265, 1-13. https://doi.org/10.1016/j.socscimed.2020.113466

Arias, E., \& Xu, J. (2019, June 24). United States life tables, 2017. (National Vital Statistics Reports, vol. 68, no. 7). National Center for Health Statistics. https://www.cdc.gov/nchs/data/nvsr/nvsr68/nvsr68 07-508.pdf

Barclay, K., Keenan, K., Grundy, E., Kolk, M., \& Myrskylä, M. (2016). Reproductive history and post-reproductive mortality: A sibling comparison analysis using Swedish register data. Social Science \& Medicine, 155, 82-92. https://doi.org/10.1016/j.socscimed.2016.02.043

Barclay, K., \& Kolk, M. (2015). Birth order and mortality: A population-based cohort study. Demography, 52(2), 613-639. https://doi.org/10.1007/s13524-015-0377-2

Barclay, K., \& Kolk, M. (2019). Parity and mortality: An examination of different explanatory mechanisms using data on biological and adoptive parents. European Journal of Population, 35, 63-85. https://doi.org/10.1007/s10680-018-9469-1

Barclay, K. J., \& Kolk, M. (2017). The long-term cognitive and socioeconomic consequences of birth intervals: A within-family sibling comparison using Swedish register data.

Demography, 54(2), 459-484. https://doi.org/10.1007/s13524-017-0550-x

Berg, V., \& Rotkirch, A. (2014). Faster transition to the second child in late 20th century Finland: A study of birth intervals. Finnish Yearbook of Population Research, 49, 73-86. https://doi.org/10.23979/fypr.48424

Box-Steffensmeier, J. M., \& Jones, B. S. (2004). Event history modeling: A guide for social scientists. Cambridge University Press. https://doi.org/10.1017/CBO9780511790874

Colyer, C., Anderson, C., Stein, R., Donnermeyer, J. F., \& Wasao, S. (2017). Reviving the demographic study of the Amish. Journal of Amish and Plain Anabaptist Studies, 5(1), 96119. https://doi.org/10.18061/1811/81073

Cooper, G. S., Baird, D. D., Weinberg, C. R., Ephross, S. A., \& Sandler, D. P. (2000). Age at menopause and childbearing patterns in relation to mortality. American Journal of Epidemiology, 151(6), 620-623. https://doi.org/10.1093/oxfordjournals.aje.a010250

Corcoran, K. E., Stein, R. E., Colyer, C. J., \& Kowalski, B. (2020). Familial ties, location of occupation, and congregational exit in geographically-based congregations: A case study of the Amish. Review of Religious Research. Advance online publication.

https://doi.org/10.1007/s13644-020-00438-7 
Cox, D. R. (1972). Regression models and life-tables. Journal of the Royal Statistical Society. Series B (Methodological), 34(2), 187-202. https://doi.org/10.1111/j.2517$\underline{6161.1972 . t b 00899 . x}$

Cross, H. E., \& McKusick, V. A. (1970). Amish demography. Social Biology, 17(2), 83-101. https://doi.org/10.1080/19485565.1970.9987850

Doblhammer, G. (2000). Reproductive history and mortality later in life: A comparative study of England and Wales and Austria. Population Studies, 54(2), 169-176. https://doi.org/10.1080/713779087

Donnermeyer, J. F. (2015). Doubling time and population increase of the Amish. Journal of Amish and Plain Anabaptist Studies, 3(1), 94-109. https://doi.org/10.18061/1811/69364

Donnermeyer, J. F., Anderson, C., \& Cooksey, E. C. (2013). The Amish population: County estimates and settlement patterns. Journal of Amish and Plain Anabaptist Studies, 1(1), 72 109. https://doi.org/10.18061/1811/54896

Dorsten, L. E. (1994). Direct and indirect effects on infant mortality in a high-fertility U.S. population. Population Research and Policy Review, 13(1), 31-48. https://doi.org/10.1007/BF01074320

Ellison, C. G., \& Levin, J. S. (1998). The religion-health connection: Evidence, theory, and future directions. Health Education \& Behavior, 25(6), 700-720. https://doi.org/10.1177/109019819802500603

Ericksen, J. A., Ericksen, E. P., Hostetler, J. A., \& Huntington, G. E. (1979). Fertility patterns and trends among the Old Order Amish. Population Studies, 33(2), 255-276. https://doi.org/10.1080/00324728.1979.10410441

Fox-Kuhner, S. (2008). Cultural factors influencing prenatal care in the Amish. (Publication No. 1461801) [Master's thesis, Mountain State University]. ProQuest Dissertations Publishing.

Friedman, E. M., \& Mare, R. D. (2014). The schooling of offspring and the survival of parents. Demography, 51(4), 1271-1293. https://doi.org/10.1007/s13524-014-0303-Z

Fuchs, J. A., Levinson, R. M., Stoddard, R. R., Mullet, M. E., \& Jones, D. H. (1990). Health risk factors among the Amish: Results of a survey. Health Education Quarterly, 17(2), 197-211. https://doi.org/10.1177/109019819001700206

Greksa, L. P. (2002). Population growth and fertility patterns in an Old Order Amish settlement. Annals of Human Biology, 29(2), 192-201. https://doi.org/10.1080/03014460110075684

Greksa, L. P. (2004). Birth seasonality in the Old Order Amish. Journal of Biosocial Science, 36(3), 299-315. https://doi.org/10.1017/S0021932003006254

Grundy, E., \& Kravdal, Ø. (2014). Do short birth intervals have long-term implications for parental health? Results from analyses of complete cohort Norwegian register data. Journal of Epidemiology \& Community Health, 68(10), 958-964. https://doi.org/10.1136/jech-2014$\underline{204191}$

Grundy, E., \& Shelton, N. (2001). Contact between adult children and their parents in Great Britain 1986-99. Environment and Planning A: Economy and Space, 33(4), 685-697. https://doi.org/10.1068/a33165 
Grundy, E., \& Tomassini, C. (2005). Fertility history and health in later life: A record linkage study in England and Wales. Social Science \& Medicine, 61(1), 217-228.

https://doi.org/10.1016/j.socscimed.2004.11.046

Hewner, S. J. (1998). Fertility, migration, and mortality in an Old Order Amish community. American Journal of Human Biology, 10(5), 619-628. https://doi.org/10.1002/(SICI)15206300(1998)10:5<619::AID-AJHB8>3.0.CO;2-8

Högnäs, R. S., Roelfs, D. J., Shor, E., Moore, C., \& Reece, T. (2017). J-curve? A meta-analysis and meta-regression of parity and parental mortality. Population Research and Policy Review, 36(2), 273-308. https://doi.org/10.1007/s11113-016-9421-1

Hostetler, J. A. (1993). Amish society (4th ed.). Johns Hopkins University Press.

Hurst, C. E., \& McConnell, D. L. (2010). An Amish paradox: Diversity and change in the world's largest Amish community. Johns Hopkins University Press.

Hurt, L. S., Ronsmans, C., \& Thomas, S. L. (2006). The effect of number of births on women's mortality: Systematic review of the evidence for women who have completed their childbearing. Population Studies, 60(1), 55-71. https://doi.org/10.1080/00324720500436011

Institute for Health Metrics and Evaluation. (2016). U.S. County Profile: Holmes County, Ohio. http://www.healthdata.org/sites/default/files/files/county_profiles/US/2015/County_Report Holmes_County Ohio.pdf

Joshi, H. (2002). Production, reproduction, and education: Women, children, and work in a British perspective. Population and Development Review, 28(3), 445-474. https://doi.org/10.1111/j.1728-4457.2002.00445.x

Kawachi, I. (2019). Invited commentary: Religion as a social determinant of health. American Journal of Epidemiology, 189(12), 1461-1463. https://doi.org/10.1093/aje/kwz204

Kraybill, D. B. (2001). The riddle of Amish culture. (Rev. ed.). Johns Hopkins University Press.

Kraybill, D. B., Johnson-Weiner, K. M., \& Nolt, S. M. (2013). The Amish. Johns Hopkins University Press.

Kreps, G. M., Donnermeyer, J. F., \& Kreps, M. W. (1994). The changing occupational structure of Amish males. Rural Sociology, 59(4), 708-719. https://doi.org/10.1111/j.15490831.1994.tb00556.x

Lucas, C. A., O’Shea, R. M., Zielezny, M. A., Freudenheim, J. L., \& Wild, J. F. (1991). Rural medicine and the closed society. Pregnancy outcomes among Amish and non-Amish women. New York State Journal of Medicine, 91(2), 49-52.

Merrill, R. M., Fugal, S., Novilla, L. B., \& Raphael, M. C. (2005). Cancer risk associated with early and late maternal age at first birth. Gynecologic Oncology, 96(3), 583-593. https://doi.org/10.1016/j.ygyno.2004.11.038

Miller, K., Yost, B., Flaherty, S., Hillemeier, M. M., Chase, G. A., Weisman, C. S., \& Dyer, A.M. (2007). Health status, health conditions, and health behaviors among Amish women: Results from the Central Pennsylvania Women's Health Study (CePAWHS). Women's Health Issues, 17(3), 162-171. https://doi.org/10.1016/j.whi.2007.02.011 
Mitchell, B. D., Lee, W.-J., Tolea, M. I., Shields, K., Ashktorab, Z., Magder, L. S., Ryan, K. A., Pollin, T. I., McArdle, P. F., Shuldiner, A. R., \& Schäffer, A. A. (2012). Living the good life? Mortality and hospital utilization patterns in the Old Order Amish. PLoS ONE, 7(12), e51560. https://doi.org/10.1371/journal.pone.0051560

Nolt, S. M. (2016). The Amish: A concise introduction. Johns Hopkins University Press.

Read, S., Grundy, E., \& Wolf, D. A. (2011). Fertility history, health, and health changes in later life: A panel study of British women and men born 1923-49. Population Studies, 65(2), 201215. https://doi.org/10.1080/00324728.2011.572654

St. George, D., Everson, P. M., Stevenson, J. C., \& Tedrow, L. (2000). Birth intervals and early childhood mortality in a migrating Mennonite community. American Journal of Human Biology, 12(1), 50-63. https://doi.org/10.1002/(SICI)1520-6300(200001/02)12:1<50::AIDAJHB7>3.0.CO;2-X

Stevenson, J. C., Everson, P. M., \& Crawford, M. H. (1989). Changes in completed family size and reproductive span in Anabaptist populations. Human Biology, 61(1), 99-115.

Torssander, J. (2013). From child to parent? The significance of children's education for their parents' longevity. Demography, 50(2), 637-659. https://doi.org/10.1007/s13524-012-0155-3

U.S. Census Bureau. (n.d.). Families and households. U. S. Department of Commerce. Retrieved November 6, 2020, from https://www.census.gov/topics/families/families-andhouseholds.html

Westendorp, R. G. J., \& Kirkwood, T. B. L. (1998). Human longevity at the cost of reproductive success. Nature, 396(6713), 743-746. https://doi.org/10.1038/25519

Winikoff, B. (1983). The effects of birth spacing on child and maternal health. Studies in Family Planning, 14(10), 231-245. https://doi.org/10.2307/1965748

Yi, Z., \& Vaupelly, J. (2004). Association of late childbearing with healthy longevity among the oldest-old in China. Population Studies, 58(1), 37-53. https://doi.org/10.1080/0032472032000175437

Zeng, Y., Ni, Z., Liu, S., Gu, X., Huang, Q., Liu, J., \& Wang, Q. (2016). Parity and all-cause mortality in women and men: A dose-response meta-analysis of cohort studies. Scientific Reports, 6, 19351. https://doi.org/10.1038/srep19351

Zimmer, Z., Hanson, H. A., \& Smith, K. R. (2016). Offspring socioeconomic status and parent mortality within a historical population. Demography, 53(5), 1583-1603.

https://doi.org/10.1007/s13524-016-0502-x 